\title{
AOR
}

Selected Papers of \#AolR2020:

The $21^{\text {st }}$ Annual Conference of the

Association of Internet Researchers

Virtual Event / 27-31 October 2020

\section{The Right to the City and Data Protection: complementary for Developing Citizen-centric Digital Cities?}

\author{
Jonas Breuer \\ Free University of Brussels \\ Dr. Jo Pierson \\ Free University of Brussels
}

Life in digital - or 'smart' - cities is mediated by the internet. In urban space that aims to integrate physical and digital worlds, information and communication technologies become ubiquitous, not least to capture and process (personal) data. There can be benefits, but cases like Sidewalk Labs in Toronto also hint at major potential for subverting exercise of citizens' rights, especially when the latter are accepted only as long as economically feasible for those who control the data (Goodman \& Powles, 2019; Zuboff, 2018). Private governance can reconfigure public values and relations between public institutions and citizens (Mosco, 2019; Swyngedouw, 2011). So, who decides what cities become, whose interests they serve?

We present ongoing research about the Right to the City (Lefebvre, 1968) and the right to personal data protection: complementary in fostering agency and protecting citizen interests in technologically-enhanced, citizen-centric cities. Lefebvre's Right to the City installs 'users' of cities at their core, enabled to change conditions of life by (re)producing all aspects of the urban, collectively and without being constrained (Harvey, 2008; Kitchin et al., 2019). Similarly, the right to data protection addresses users of technology (data subjects) whose personal data is processed. The General Data Protection Regulation (GDPR) demands to "[...] seek views of data subjects or their representatives" (EU, 2016, Art 35(9)), which could empower data subjects of digital cities: citizens (van Eck, 2019, p. 308).

Our main research question is how 'users' of cities can be represented meaningfully in processes that shape cities? Much is already written about participation (see e.g. Castelnovo et al., 2016; O'Faircheallaigh, 2010) but few have investigated it in relation to data protection. We address this gap in the four-year interdisciplinary research 
project SPECTRE ${ }^{1}$. In this paper, we present an empirical cross-case analysis of urban data processing projects affected by the GDPR. We conducted twelve interviews with people directly involved in Belgian smart city projects in November 2019, purposefully selected for their heterogeneous roles and first-hand knowledge. ${ }^{2}$ The study is rooted in the believe that technology and its use are shaped by constantly shifting networks of relationships between artefacts, users and society with an analytical equivalence of human and non-human actors. The latter is framed with the social constructivist perspectives of Science \& Technology Studies and Actor Network Theory (Callon, 1990; Lievrouw, 2014; Michael, 2016), as our guiding methodological framework. We are interested in processes that underlie those projects, to understand where citizens are or can be involved in implementing technology in urban space. A focus lies on Data Protection Impact Assessments (DPIA) as concrete instruments of inclusion in the GDPR.

For public administrations, processing personal data is a standard task. Data security is prioritised and involving stakeholders is not considered. The interviews show that typical smart city projects (e.g. tracking of passers-by), however, often seem to start because 'there is a solution, so let's find a problem', 'the more data the better', PR, or the inevitability of 'because everyone becomes smart'. All interviewees were affected by stricter data protection rules in the GDPR and described frustrations or perceived barriers to innovation. The projects without a clear purpose that is related to serving citizen needs experienced more tensions, were delayed longer or even have to be cancelled. Involving views of citizens at an early stage before a project to co-decide whether it should be started, as some interviewees have mentioned, seems especially important in the light of the rights discussed above. The interviews illustrated that diverse agendas and processing purposes of public and private actors in the projects make it challenging to legally formalise relationships and define roles and responsibilities through contracts and agreements. Actors seem to be hesitant to take legal responsibility, which is often related to uncertainty about obligations and fines. Citizens largely seem to remain without real agency or power to influence decisionmaking. Actual moments of public participation in DPIAs as suggested by the regulation are not common, not least due to lack of budget or time and other priorities.

Our study illustrates that data protection impacts smart city developments, but true agency of citizens as in the Right to the City remains limited. It shows that researchers can contribute to lowering barriers to participation in practice: by addressing practicalities such as costs and expertise, by raising capabilities, by developing specific methods and techniques for participation in this context. Interdisciplinary expertise is required to further understanding in this complex, cross-domain environment. We focus on these aspects and continue researching how meaningful involvement can be facilitated in urban development.

\footnotetext{
${ }^{1}$ SPECTRE (Smart city Privacy: Enhancing Collaborative Transparency in the Regulatory Ecosystem) is funded by the Flemish region and allows three research centres of different disciplines to combine their expertise and investigate the potential of data protection and in particular Data Protection Impact Assessments in strengthening the role of citizens in smart cities.

${ }^{2}$ We interviewed DPOs of cities and companies, smart city project owners, legal advisors, the CEO of a start-up, user involvement specialists, public servants directly involved in processing personal data, representatives of a data protection authority and an adviser to a major city in the Netherlands. The interviews were transcribed and analysed with the qualitative research software MAXQDA.
} 


\section{References}

Callon, M. (1990). Techno-economic Networks and Irreversibility. The Sociological Review, 38(1_suppl), 132-161. https://doi.org/10.1111/j.1467954X.1990.tb03351.x

Castelnovo, W., Misuraca, G., \& Savoldelli, A. (2016). Smart Cities Governance: The Need for a Holistic Approach to Assessing Urban Participatory Policy Making. Social Science Computer Review, 34(6), 724-739. https://doi.org/10.1177/0894439315611103

EU. (2016). Regulation (EU) 2016/679 of the european parliament and of the council on the protection of natural persons with regard to the processing of personal data and on the free movement of such data.

Goodman, E. P., \& Powles, J. (2019). Urbanism Under Google: Lessons from Sidewalk Toronto. SSRN Electronic Journal. https://doi.org/10.2139/ssrn.3390610

Harvey, D. (2008). The Right to the City. New Left Review, 53, 23-40.

Kitchin, R., Cardullo, P., \& Feliciantonio, C. D. (2019). Citizenship, Justice and the Right to the Smart City. In THE RIGHT TO THE SMART CITY (p. 28). Emerald Publishing.

Lefebvre, H. (1968). Le droit à la ville. SEUIL.

Lievrouw, L. A. (2014). Chapter 2) Materiality and Media in Communication and Technology Studies: An Unfinished Project. In T. Gillespie, P. J. Boczkowski, \& K. A. Foot (Eds.), Media technologies: Essays on communication, materiality, and society (pp. 21-51). The MIT Press.

Michael, M. (2016). Actor network theory: Trials, trails and translations (1st edition). SAGE Ltd.

Mosco, V. (2019). The smart city in a digital world: Vincent Mosco.

O'Faircheallaigh, C. (2010). Public participation and environmental impact assessment: Purposes, implications, and lessons for public policy making. Environmental Impact Assessment Review, 30(1), 19-27. https://doi.org/10.1016/j.eiar.2009.05.001

Swyngedouw, E. (2011). The Zero-Ground of Politics: Musings on the Post-Political City. In T. Kaminer \& M. Robles-Duran (Eds.), Urban Asymmetries: Studies and Projects on Neoliberal Urbanization. 010.

van Eck, G. J. R. (2019). Algortithmic Mapmaking in 'Smart Cities': Data Protection Impact Asessments as a means of Protection for Groups. In Good data (pp. 298316). Institute of Network Cultures (Amsterdam).

Zuboff, S. (2018). The age of surveillance capitalism: The fight for a human future at the new frontier of power (First edition). PublicAffairs. 